\title{
The Influence of an EPS Concrete Buffer Layer Thickness on Debris Dams Impacted by Massive Stones in the Debris Flow
}

\author{
Xianbin Yu, ${ }^{1,2,3}$ Xiaoqing Chen,, Wanyu Zhao, ${ }^{1,2}$ and Jiangang Chen ${ }^{1,2}$ \\ ${ }^{1}$ Institute of Mountain Hazards and Environment, Chinese Academy of Sciences, Chengdu 610041, China \\ ${ }^{2}$ Key Laboratory of Mountain Hazards and Surface Processes, Chinese Academy of Sciences, Chengdu 610041, China \\ ${ }^{3}$ University of Chinese Academy of Sciences, Beijing 100049, China
}

Correspondence should be addressed to Xiaoqing Chen; xqchen@imde.ac.cn

Received 7 May 2015; Revised 13 July 2015; Accepted 15 July 2015

Academic Editor: Sakdirat Kaewunruen

Copyright (C) 2015 Xianbin Yu et al. This is an open access article distributed under the Creative Commons Attribution License, which permits unrestricted use, distribution, and reproduction in any medium, provided the original work is properly cited.

\begin{abstract}
The failure of debris dams impacted by the massive stones in a debris flow represents a difficult design problem. Reasonable materials selection and structural design can effectively improve the resistance impact performance of debris dams. Based on the cushioning properties of expanded polystyrene (EPS) concrete, EPS concrete as a buffer layer poured on the surface of a rigid debris dam was proposed. A three-dimensional numerical calculation model of an EPS concrete buffer layer/rigid debris dam was established. The single-factor theory revealed change rules for the thickness of the buffer layer concerning the maximal impact force of the rigid debris dam surface through numerical simulation. Moreover, the impact force-time/history curves under different calculation conditions for the rigid debris dam surface were compared. Simulation results showed that the EPS concrete buffer layer can not only effectively extend the impact time of massive stones affecting the debris dam but also reduce the impact force of the rigid debris dam caused by massive stones in the debris flow. The research results provide theoretical guidance for transferring the energy of the massive stone impact, creating a structural design and optimizing debris dams.
\end{abstract}

\section{Introduction}

Because of their detrimental consequences-for example, injuries and economic losses related to damage to buildings, industrial facilities, and infrastructure-debris flows are among the most dangerous natural phenomena. There are many types of debris flow-control engineering, such as debris dams (check dams), grille dams, drainage canals, and stopand-deposit fields. The debris dam is one of the most effective methods to control debris flow. A debris dam can effectively intercept solid particles in the debris flow and reduce its destructive power in downstream areas. Existing debris dams are mainly built of concrete or grouted rubble, which can not only block coarse particles but also drain away fine particles and slurry; however, a rigid debris dam is vulnerable to being washed away by the force of a debris flow's impact, especially when that force is caused by massive stones in the debris flow. Large-scale debris flow in the mountainous part of Sichuan and southern Gansu is very common because of the area's extreme weather and the May 12 Wenchuan earthquake.
Large-scale debris flow usually includes massive stones. In the Wenjiagou "8.13" catastrophic debris flow [1], the scale of those stones was $3.0 \mathrm{~m} \times 2.5 \mathrm{~m} \times 1.6 \mathrm{~m}$. In the Sanyanyu gully of the Zhouqu county " 8.8 " catastrophic debris flow, the stones were $7.5 \mathrm{~m} \times 7.0 \mathrm{~m} \times 5.5 \mathrm{~m}$. These stones can achieve speeds of $8 \sim 12 \mathrm{~m} / \mathrm{s}$, and their impact force is as high as $2 \sim 7 \times$ $10^{7} \mathrm{~N}$ [2]. The impact of massive stones can shorten a debris dam's working life or destroy the debris dam. Thus, it is a major challenge to improve debris dams' resistance-impact performance [3].

Many scholars have researched new materials and structures to resolve the abovementioned issues. Wang and Zheng have designed a new support with a spring, which has been used in a new debris-flow dam. Their results show the impactresisting effect of the new support [4]. The Institute of Water Conservancy Project and Soil Improvement (Georgia) has designed a combination structure containing elastic steel cable obstruction, an elastic steel-cable-distribution network, and a multistage stopped tilt-flow frame to control debris flow [5]. Su et al. have designed a flexible gabion-arch 
dam to decrease the impact force of debris flow. Numerical simulation was performed using ANSYS LS-DYNA software, focusing on the structure's dynamic response to the impact of debris flow. The results indicated that the flexible arch structure effectively reduced both impact force and mudflow pressure through appropriate deformation [6]. Luo et al. have presented a new method of preventing rolling stones disaster, which places waste tires in front of the rigid rolling stones barrier to form a rigid, flexible structure system. Using the FEM software LS-DYNA to analyze the energy consumption of waste tires under rolling stones, the results indicate that the waste tires have good energy absorption, which is useful for improving the rigid rolling stones barrier [7]. Wang et al. have studied the attenuation law of the stress wave in concrete containing EPS interlayers by numerical simulation [8]. Using numerical simulation, Wang et al. conducted research on the propagation law of explosion waves in protective structures containing expanded polystyrene (EPS) cushions [9]. EPS cushions and foamed aluminum cushions have been proposed to buffer the impact effect of rolling stones on the rock-shed, and the mechanism of energy dissipation for the abovementioned buffer material has been studied [10]. The abovementioned studies play an important role in improving structure-resistance impact.

That notwithstanding, new debris-flow dams with spring support and debris-flow elastic-steel-cable obstructions have disadvantages: they consume a large amount of steel, require complex structures, and have poor practicability. Although flexible gabion-arch dams have the advantage of comprising simple structures, they cannot be used to control and prevent large-scale debris flow; moreover, they have a short working life. It is practical to use the elasticity and toughness of waste tires to relieve the impact force of rolling stones, but forming a complete whole between waste tires and the structure surface remains a difficult problem. Because of the use of low-intensity EPS material, the buffering effect is poor when using separate EPS interlayers. To further improve the impact resistance of the structures, some academics have not only performed numerical simulation and experimental research on foam concrete as a protective energy-absorption cushion but also provided empirical formulas [11]. However, foam concrete exhibits poor energy-absorption behavior because its particle size is inconsistent, resulting in mechanically unstable properties, and the foam is easily overwhelmed [12]. Bischoff et al. have proposed that EPS concrete has a strong energy-absorption function, and EPS concrete can be used as the protective layer for the protective structure [13]. Compared with the abovementioned energy-absorption cushion, EPS concrete has the following advantages. Firstly, the particle size of the foam is determined by the particle size of the EPS, which is consistent. Secondly, using the EPS particles to support the concrete cell is conducive to the stability of the cell's mechanical behavior, and the EPS particles greatly improve the stability of the concrete cells. Thirdly, EPS material and concrete material are combined to form a whole; EPS particles are bound around the concrete material during deformation, which strengthens the EPS particles. Therefore, the EPS concrete has good ductility and toughness, thus reflecting significant energy absorption [12]. The rigid debris dam surface is treated with adhesives, structural adhesives, and other means of forming the EPS and rigid debris dam as a whole. Two lines of defense are formed to resist the impact of debris flow and massive stones using the energy-absorbing effect of the EPS buffer and the intensity of the rigid debris dam. Based on previous research, pouring EPS concrete as a buffer layer on the surface of the rigid debris dam is proposed. A threedimensional numerical calculation model of the EPS concrete buffer layer/rigid debris dam is established. According to the results of the numerical simulation, the recommended formula for the optimum thickness of the buffer layer is given.

\section{The Composite Structure: A Brief Introduction to the EPS Concrete Buffer Layer/Rigid Debris Dam}

Massive stones in a debris flow have a high impact force. The failure of debris dams impacted by massive stones in a debris flow poses a difficult design problem. Reasonable materials selection and structural design can effectively improve the resistance-impact performance of debris dams. EPS concrete has an obvious yield platform when impacting. The strain increases, whereas stress remains unchanged, thus indicating both that EPS concrete has good impacting-compression ability and that EPS particles have high energy-absorption characteristics [14-16]. Expanded polystyrene concrete (EPS concrete) is made of EPS particles, coarse sand gravel, cement, water, additives, and other materials, with a certain mixing ratio. EPS concrete is a new material with a low apparent density, good energy absorption, low cost, and high economic and social benefits. The difference between EPS concrete and ordinary concrete is their weaknesses. The mesh cement mortar of ordinary concrete surrounded by and bonded with stronger and stiffer aggregate is the weak part of the structure. However, EPS concrete's cement mortar is surrounded and bonded not only with aggregate but also with EPS particles, which give the EPS concrete different properties. Additionally, EPS concrete is a significant yield concrete platform. The stress-strain curves of concrete and EPS concrete are shown in Figure 1. EPS concrete as a buffer layer poured on the surface of the rigid debris dam was proposed because of its cushioning properties. Two lines of defense are formed to resist the impact of debris flow and massive stones by using the energy-absorbing effect of the EPS buffer and the intensity of the rigid debris dam. A diagrammatic cross section of the EPS concrete buffer layer/rigid debris dam is shown in Figure 2.

In Figure 1,oa and $o c$ stand for the elastic stage, points $a$ and $c$ stand for the elastic limit, points $b$ and $e$ stand for the ultimate strength, and de stands for the yielding platform. In Figure 2, $A$ stands for the upper width of the debris dam section, $B$ stands for the bottom width of the debris dam section, and $H$ stands for the effective height of the debris dam. 


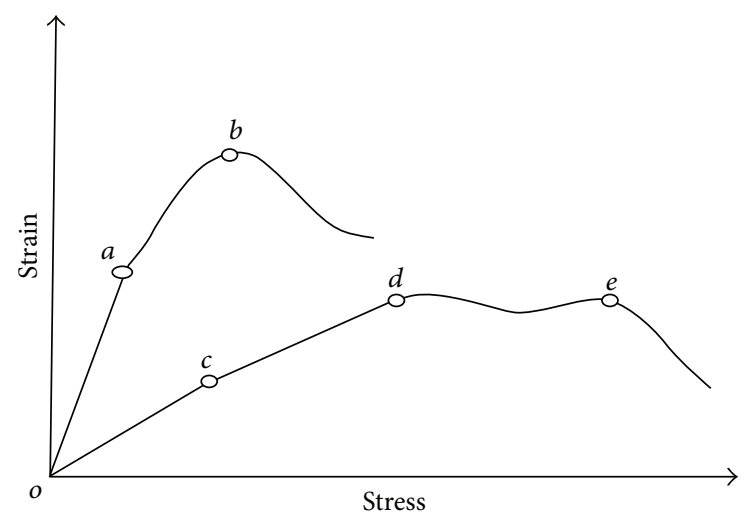

FIGURE 1: Stress-strain curve of concrete and EPS concrete [28].

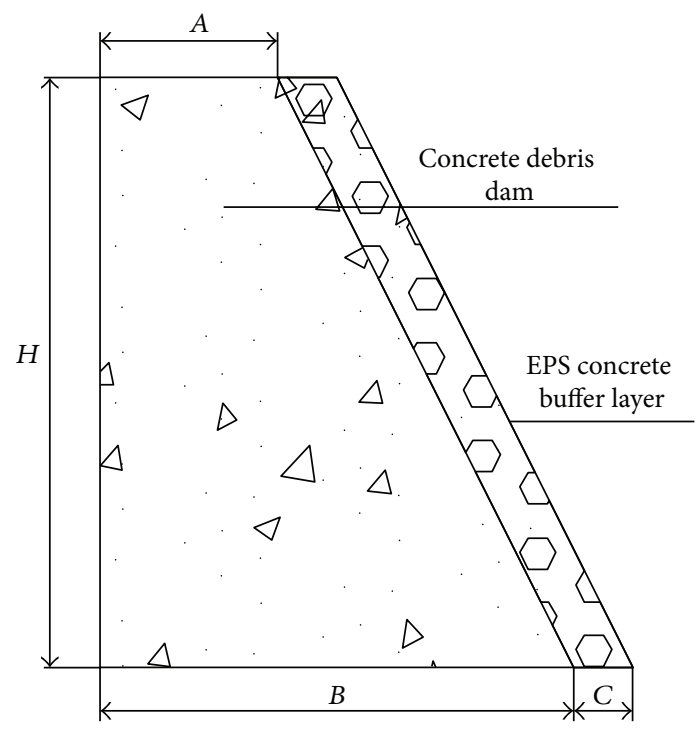

FIGURE 2: Diagrammatic cross section of an EPS concrete buffer layer/rigid debris dam.

\section{The Impact Energy of Massive Stones in the Debris Flow}

Massive stones impact the debris dam with kinetic energy, which comprises all of the impact energy. The impact energies of the massive stones are obtained using the theorem of kinetic energy. The mathematical expression is

$$
Q=E=\frac{1}{2} m v^{2}
$$

where $Q$ is the impact energy of the massive stones in the debris flow $(\mathrm{KJ}), E$ is the kinetic energy of the massive stones in the debris flow $(\mathrm{KJ}), m$ is the mass of the massive stones in the debris flow ( $\mathrm{t})$, and $V$ is the impact velocity of the massive stones in the debris flow $(\mathrm{m} / \mathrm{s})$.

\section{Numerical Model and Pretreatment}

4.1. Establishing the Numerical Model. A debris dam is primarily constructed from $\mathrm{C} 15$ concrete, and the numerical

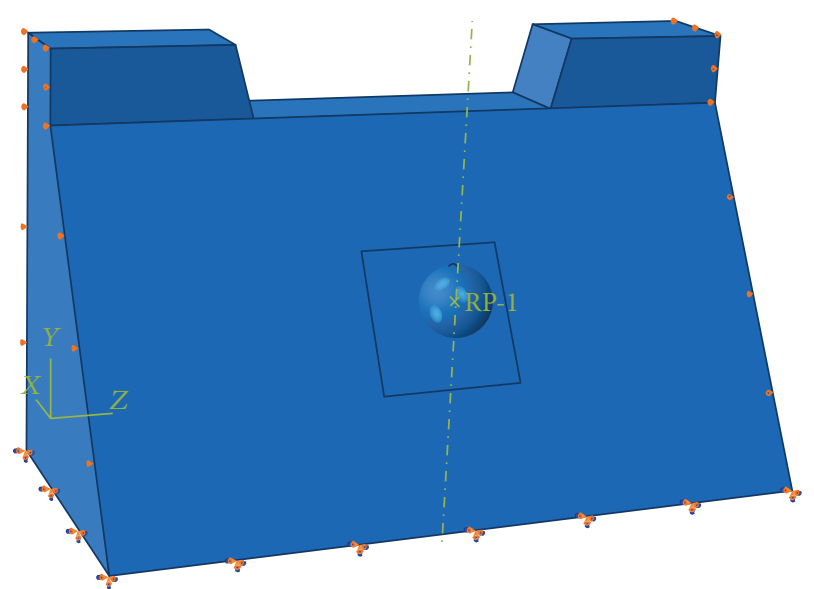

FIGURE 3: A sketch of the three-dimensional geometry model of the debris dam and boundary condition.

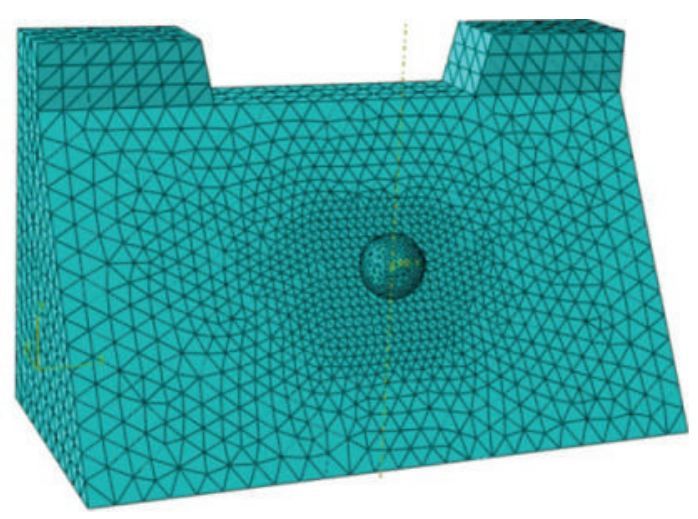

FIgURE 4: Meshing the debris dam and massive stones.

calculation does not consider hierarchical placement, so the effect of reinforcement on concrete strength is ignored. The upper part of the debris dam section is $2.5 \mathrm{~m}$, the underside is $8.5 \mathrm{~m}$, the effective height of the debris dam is $10 \mathrm{~m}$, and the length of the dam is $20 \mathrm{~m}$. The front of the debris dam slope is $1: 0.5$, and the back-side slope is vertical. The length of the top edge of the overflow mouth is $10 \mathrm{~m}$, whereas the length of the bottom edge is $9 \mathrm{~m}$, and the height of the overflow mouth is $2 \mathrm{~m}$. The massive stone is simplified as a sphere, and the diameter is $2 \mathrm{~m}$. A buffer layer of EPS concrete is poured to a particular thickness on the upstream face of the rigid debris dam. The three-dimensional geometry model of the EPS concrete buffer layer/rigid debris dam and the stones are shown in Figure 3.

4.2. Meshing. Grid quality directly affects the results of the finite element analysis. The primary analysis involves the changed regulation of the impact stress and impact force of the debris-dam contact surface, thus refining the grid in the vicinity of the contact surface and increasing the grid far from the contact surface to meet the requirements of numericalsimulation accuracy and speed [17]. Grid partitioning is shown in Figure 4. 
TABLE 1: Mathematical and mechanical parameters of the material $[12,20,26,29,30]$.

\begin{tabular}{|c|c|c|c|c|c|c|c|c|}
\hline Materials & $\begin{array}{c}\text { Density } \\
\rho\left(\mathrm{kg} / \mathrm{m}^{3}\right)\end{array}$ & $\begin{array}{c}\text { Elastic modulus } \\
E(\mathrm{GPa})\end{array}$ & $\begin{array}{l}\text { Poisson } \\
\text { ratio } \mu\end{array}$ & Dilatancy $\left({ }^{\circ}\right)$ & Eccentricity & $\begin{array}{c}\text { Biaxial limit compressive } \\
\text { strength/uniaxial limit } \\
\text { compressive strength } \\
f_{b 0} / f_{c 0}\end{array}$ & $\begin{array}{l}\text { Constant } \\
\text { stress ratio } \\
\quad k\end{array}$ & $\begin{array}{l}\text { Viscosity } \\
\text { parameter }\end{array}$ \\
\hline Massive stone & 2,650 & 40 & 0.25 & - & - & - & - & - \\
\hline Concrete & 2,400 & 26.48 & 0.2 & 30 & 0.1 & 1.16 & 0.6667 & 0.0005 \\
\hline EPS concrete & 890 & $5.1 e-3$ & 0.17 & - & - & - & - & - \\
\hline
\end{tabular}

4.3. Material Parameters and Constitutive Model. The massive stones act as a concentrated force on the debris dam; moreover, the massive stone itself has a very irregular shape. For the sake of convenience, each massive stone is simplified as a sphere, according to the principle of keeping the stone volume unchanged $[18,19]$.

Without considering the plastic deformation of massive stones, the elastic model is used to describe the stone's constitutive relation. Consider the plastic deformation of the EPS concrete buffer layer and concrete. The crushable foam model and concrete elastoplastic damage model are used to express the constitutive relation of the EPS concrete buffer layer and the concrete, respectively. Using concrete with $40 \%$ EPS and referring to the literature [12], the stressstrain curves are obtained. The concrete damaged-plasticity model is used to express the concrete's constitutive relation. Referring to the literature [20], the behavior of concrete tensile and concrete compression and damage factors are obtained. The mechanical parameters are shown in Table 1.

4.3.1. The Elastic Model. The elastic model includes the following three groups of equations [21-25].

\section{(1) Equilibrium Differential Equations. Consider}

$$
\begin{aligned}
& \frac{\partial \sigma_{x}}{\partial x}+\frac{\partial \tau_{y x}}{\partial y}+\frac{\partial \tau_{z x}}{\partial z}-f_{x}=0 \\
& \frac{\partial \sigma_{y}}{\partial y}+\frac{\partial \tau_{z y}}{\partial z}+\frac{\partial \tau_{x y}}{\partial x}-f_{y}=0 \\
& \frac{\partial \sigma_{z}}{\partial z}+\frac{\partial \tau_{x z}}{\partial x}+\frac{\partial \tau_{y z}}{\partial y}-f_{z}=0
\end{aligned}
$$

where $\sigma_{x}, \sigma_{y}$, and $\sigma_{z}$ are the normal stress, $\tau_{x y}, \tau_{y z}$, and $\tau_{z x}$ are the shear stress, $\alpha$ is a coefficient from 0 to $1, d$ is the pore pressure, and $f_{x}, f_{y}$, and $f_{z}$ are the volume force of the directions $x, y$, and $z$, respectively.

\section{(2) Geometric Equations. Consider}

$$
\begin{aligned}
\varepsilon_{x} & =\frac{\partial u}{\partial x} \\
\varepsilon_{y} & =\frac{\partial v}{\partial y}
\end{aligned}
$$

$$
\begin{aligned}
\varepsilon_{z} & =\frac{\partial w}{\partial z} \\
\gamma_{x y} & =\frac{\partial v}{\partial x}+\frac{\partial u}{\partial y}, \\
\gamma_{y z} & =\frac{\partial w}{\partial y}+\frac{\partial v}{\partial z} \\
\gamma_{z x} & =\frac{\partial u}{\partial z}+\frac{\partial w}{\partial x}
\end{aligned}
$$

where $\varepsilon_{x}, \varepsilon_{y}$, and $\varepsilon_{z}$ are the normal strains, $\gamma_{x y}, \gamma_{y z}$, and $\gamma_{z x}$ are the shear strains, and $u, v$, and $w$ are the displacements.

(3) Constitutive Equations. Consider

$$
\begin{aligned}
\varepsilon_{x} & =\frac{1}{E}\left[\sigma_{x}-\mu\left(\sigma_{y}+\sigma_{z}\right)\right], \\
\varepsilon_{y} & =\frac{1}{E}\left[\sigma_{y}-\mu\left(\sigma_{z}+\sigma_{x}\right)\right], \\
\gamma_{x y} & =\frac{2(1+\mu)}{E} \tau_{x y}, \\
\gamma_{y z} & =\frac{2(1+\mu)}{E} \tau_{y z}, \\
\gamma_{z x} & =\frac{2(1+\mu)}{E} \tau_{z x},
\end{aligned}
$$

where $E$ is the modulus of elasticity and $\mu$ is Poisson's ratio.

4.3.2. Concrete Elastoplastic Damage Model. The concrete damage model is used as the concrete strength criterion. The isotropic elastic damage and the isotropic tensile and compressive plasticity theories are used to characterize the inelastic behavior of concrete, and the nonassociated multiple sclerosis plasticity and isotropic elastic damage theories are introduced to describe the irreversible damage-generating material-fracture process [26]. The expressions related to the strength criterion are as follows.

(1) Strain Rate. Consider

$$
\{d \varepsilon\}=\left\{d \varepsilon^{\mathrm{el}}\right\}+\left\{d \varepsilon^{\mathrm{pl}}\right\}
$$


where $d \varepsilon$ is the total strain rate, $d \varepsilon^{\mathrm{el}}$ is the elastic strain rate, and $d \varepsilon^{\mathrm{pl}}$ is the plastic strain rate.

\section{(2) Constitutive Equations. Consider}

$$
\sigma=(1-d) D_{0}^{\mathrm{el}}:\left(\varepsilon-\varepsilon^{\mathrm{pl}}\right)=D^{\mathrm{el}}:\left(\varepsilon-\varepsilon^{\mathrm{pl}}\right),
$$

where $D_{0}^{\mathrm{el}}$ is the initial elastic modulus, $D^{\mathrm{el}}$ is the stiffness damage modulus, and $0 \leq d \leq 1 . d=0$ when the materials are undamaged, and $d=1$ when the materials are completely damaged.

(3) Yield Conditions and Flow Rules. The yield function represents an effective stress-space plane of the damage suspension and damage state. For the nondependent plasticity damage model, the yield function can be expressed as

$$
F\left(\bar{\sigma}, \widetilde{\varepsilon}^{\mathrm{pl}}\right) \leq 0 .
$$

Plastic flow depends on the flow potential function $G(\bar{\sigma})$. The following expression can be obtained according to the nonassociated plastic flow rules:

$$
d \varepsilon^{\mathrm{pl}}=\dot{\lambda} \frac{\partial G(\bar{\sigma})}{\partial \bar{\sigma}} .
$$

4.3.3. Crushable Foam Model [27]. The crushable foam model with isotropic hardening uses a yield surface that is an ellipse centered at the origin of the $p-q$ stress plane. The yield surface evolves in a self-similar manner, and the evolution is governed by the equivalent plastic strain.

(1) Yield Surface. The yield surface for the isotropic hardening model is defined as

$$
F=\sqrt{q^{2}+\alpha^{2} p^{2}}-N=0,
$$

where $p=-(1 / 3)$ trace $\sigma$ is the pressure stress, $q=$ $\sqrt{(3 / 2) S: S}$ is the Mises stress, $S=\sigma+p I$ is the deviatoric stress, $N=\alpha p_{c}=\sigma_{c} \sqrt{1+(\alpha / 3)^{2}}$ is the size of the (vertical) $q$ axis of the yield ellipse, $\alpha$ is the shape factor of the yield ellipse that defines the relative magnitude of the axes, $p_{c}$ is the yield stress in hydrostatic compression, and $\sigma_{c}$ is the absolute value of the yield stress in uniaxial compression.

The yield surface represents the Mises circle in the deviatoric stress plane. The shape factor, $\alpha$, can be computed using the initial yield stress in uniaxial compression, $\sigma_{c}^{0}$, and the initial yield stress in hydrostatic compression, $p_{c}^{0}$ (the initial value of $p_{c}$ ), using the following relation:

$$
\begin{aligned}
& \alpha=\frac{3 k}{\sqrt{9-k^{2}}}, \\
& k=\frac{\sigma_{c}^{0}}{p_{c}^{0}} .
\end{aligned}
$$

(2) Flow Potential. The flow potential for the isotropic hardening model is chosen as

$$
G=\sqrt{q^{2}+\beta^{2} p^{2}},
$$

where $\beta$ represents the shape of the flow potential ellipse on the $p-q$ stress plane, which is related to the plastic Poisson ratio, $v_{p}$, via

$$
\beta=\frac{3}{\sqrt{2}} p \sqrt{\frac{1-2 v_{p}}{1+v_{p}}} .
$$

The plastic Poisson ratio, which is the ratio of the transverse to the longitudinal plastic strain under uniaxial compression, must be in the range of -1 and 0.5 , and the upper limit $\left(\nu_{p}=0.5\right)$ corresponds to the case of incompressible plastic flow $(\beta=0)$. For many low-density foams, the plastic Poisson ratio is nearly zero, which corresponds to a value of $\beta \approx 2.12$.

Plastic flow is associated when the value of $\alpha$ is the same as that of $\beta$. By default, the plastic flow is nonassociated to allow for independent calibrations of the shape of the yield surface and the plastic Poisson ratio. If you only have information about the plastic Poisson ratio and choose to use associated plastic flow, the yield stress ratio $k$ can be calculated from

$$
k=\sqrt{3\left(1-2 v_{p}\right)} .
$$

Alternatively, if only the shape of the yield surface is known and you choose to use associated plastic flow, the plastic Poisson ratio can be obtained from

$$
v_{p}=\frac{3-k^{2}}{6} \text {. }
$$

4.4. Boundary Condition and Contact Setting. The front, the black, and the upper surfaces of the debris dam are free, the bottom of the debris dam is fixed, and the $Z$-direction displacement of the debris dam shoulder is equal to 0 , as shown in Figure 3. To clearly analyze the changing rules of the impact force and the stress of the contact surface, the surface of the massive stones and the middle $4 \mathrm{~m} \times 4 \mathrm{~m}$ of the debris dam are taken as the surface contact, as shown in Figure 3.

4.5. Analysis Cases Setting. For convenience, the massivestone volume is taken as constant and the stone's impact velocity is changed to obtain different impact energies. The analysis cases are shown in Table 2.

\section{Simulation Results and Analysis}

The dynamic response of the rigid debris dam to either the same or different thickness EPS concrete buffer layers under the same or different impact velocities is analyzed according to the simulation results, and the recommended formula for the optimum thickness of the buffer layer is given.

\subsection{The Normal Contact Stress and Normal Contact Force of the Rigid Debris-Dam Contact Surface}

5.1.1. The Normal Contact Stress Nephogram and Normal Contact-Force Nephogram of the Rigid Debris-Dam Contact Surface. To compare how different thicknesses of EPS concrete buffer layers affect the normal contact stress and 
TABle 2: Analysis cases.

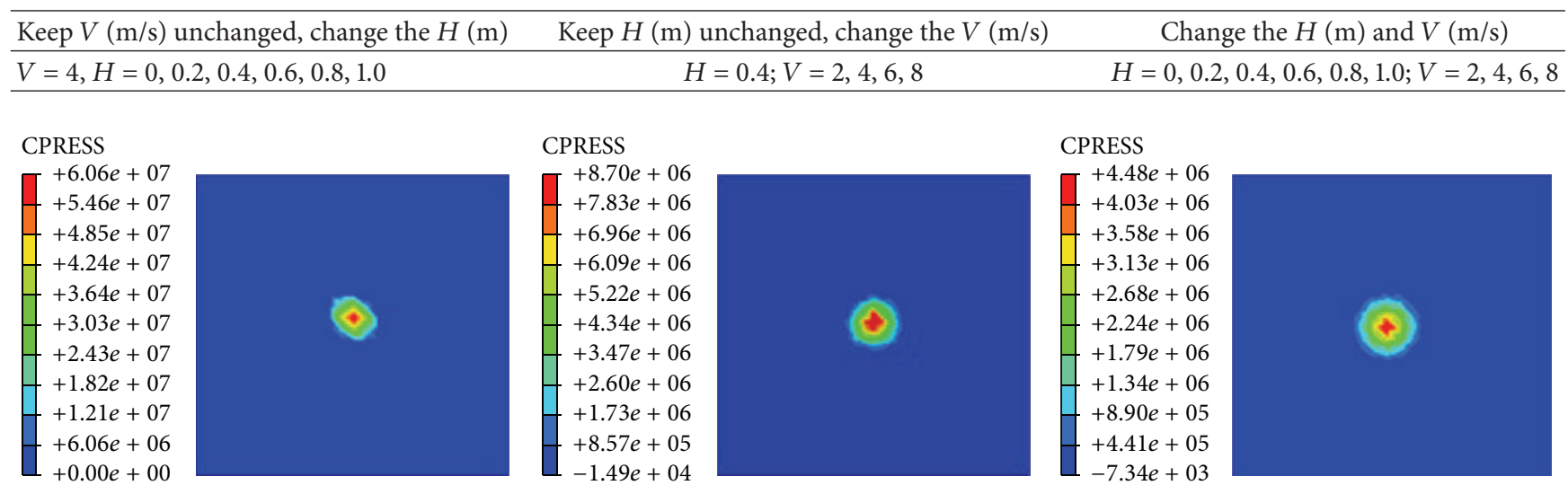

FIGURE 5: Normal contact-stress nephogram when the impact velocity is equal to $4 \mathrm{~m} / \mathrm{s}$ and the thickness of the EPS concrete buffer layer is equal to $0,0.4$, or $0.8 \mathrm{~m}$ (unit: $\mathrm{Pa}$ ).
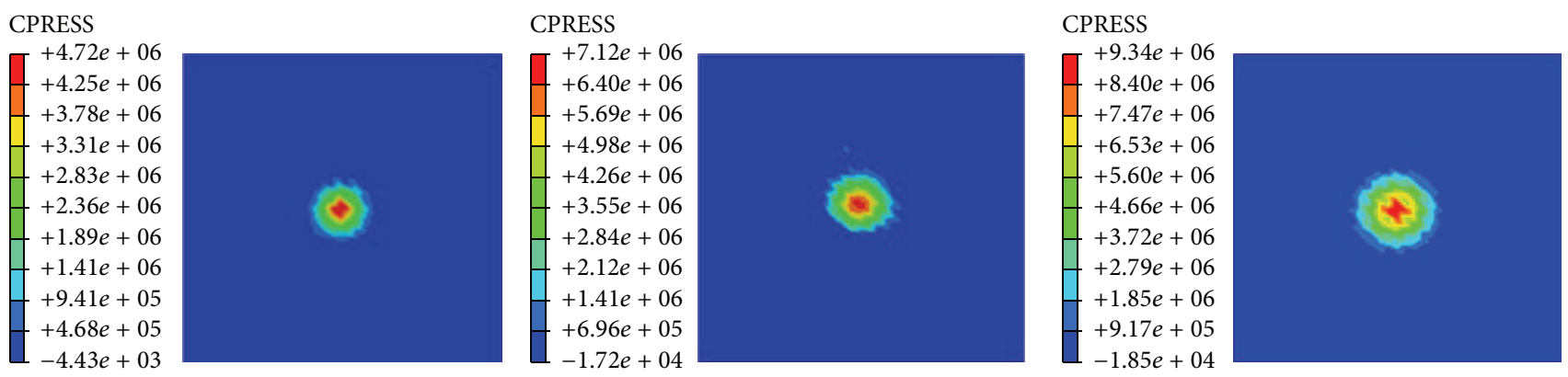

FIGURE 6: Normal contact-stress nephogram when the thickness of the EPS concrete buffer layer is equal to $0.6 \mathrm{~m}$ and the impact velocity is equal to $4 \mathrm{~m} / \mathrm{s}$ (unit: $\mathrm{Pa}$ ).

normal contact force of the rigid debris-dam contact surface, the normal contact-stress nephogram and normal contactforce nephogram of the rigid debris-dam contact surface are given when the impact velocity is equal to $4 \mathrm{~m} / \mathrm{s}$ and the thickness of the EPS concrete buffer layer is equal to $0 \mathrm{~m}, 0.4 \mathrm{~m}$, or $0.8 \mathrm{~m}$. In addition, this paper analyzes the normal contact-stress nephogram and normal contact-force nephogram of the rigid debris-dam contact surface when the thickness of the EPS concrete buffer layer is equal to $0.6 \mathrm{~m}$ and the impact velocity is equal to $4 \mathrm{~m} / \mathrm{s}$. The normal contactstress nephogram and normal contact-force nephogram of the rigid debris-dam contact surface are shown in Figures 5 to 8 .

Figures 5 and 7 show that when the stone impact speed is constant, both the contact stress and the contact force of the contact surface decrease with the increasing thickness of the buffer layer. Thus, the buffer layer plays a role in reducing the impact force and stress of a rigid debris dam that is suffering from the impact of massive stones. Figures 6 and 8 indicate that when the thickness of the buffer layer remains unchanged, the contact stress and force of the rigid debris-dam contact surface increase with the increasing impact velocity of the massive stones, which represents the same trend as the rigid surface directly suffering the impact of massive stones [17].
5.1.2. The Time-History Curve of Normal Contact Force on the Debris-Dam Contact Surface and Contact Stress on the Node with the Maximum Contact Stress. The time-history curve of the normal contact force on the debris-dam contact surface and contact stress on the node with the maximum contact stress are given in Figures 9 and 10 when the impact velocity is equal to $4 \mathrm{~m} / \mathrm{s}$ and the thickness of EPS concrete buffer layer is equal to $0 \mathrm{~m}, 0.2 \mathrm{~m}$, or $0.4 \mathrm{~m}$.

Figures 9 and 10 show that when a stone with an impact velocity of $4 \mathrm{~m} / \mathrm{s}$ directly impacts the rigid debris dam, the contact force of the debris dam-contact surface and the contact stress on the debris-dam node are far greater than when a stone with the same velocity impacts the rigid debris dam with a buffer layer. Moreover, the stone directly impacting the rigid debris dam takes less time than the stone impacting the rigid debris dam with the buffer layer, which indicates that the EPS concrete buffer layer prolongs the impact time. Prolonging the impact time helps dissipate the impact energy, which reduces the impact damage to the debris dam. The last time returns almost the same result with a $0.2 \mathrm{~m}$ EPS concrete buffer layer and a $0.4 \mathrm{~m}$ EPS concrete buffer layer; however, the contact force and the contact stress on the debris dam with a $0.4 \mathrm{~m}$ EPS concrete buffer layer are slightly less than the debris dam with a $0.2 \mathrm{~m}$ EPS concrete buffer layer. Thus, under the calculation conditions, the thickness of the buffer 
CNORMF

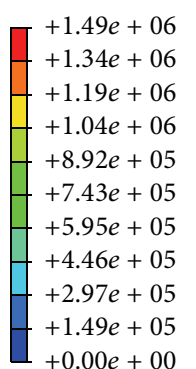

CNORMF

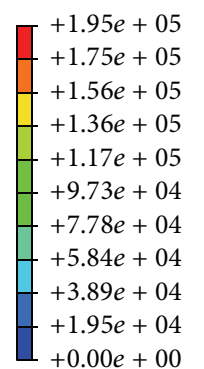

CNORMF

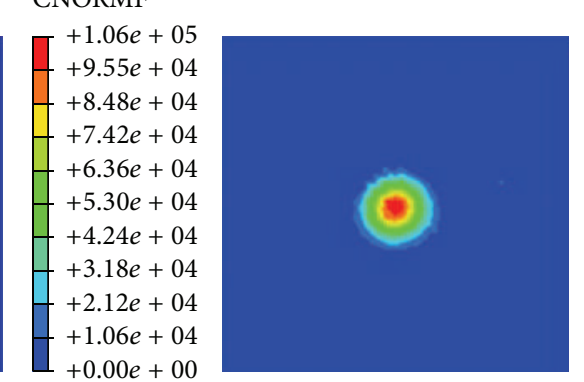

FIGURE 7: Normal contact-force nephogram when the impact velocity is equal to $4 \mathrm{~m} / \mathrm{s}$ and the thickness of the EPS concrete buffer layer is equal to $0 \mathrm{~m}, 0.4 \mathrm{~m}$, or $0.8 \mathrm{~m}$ (unit: $\mathrm{Pa}$ ).

CNORMF

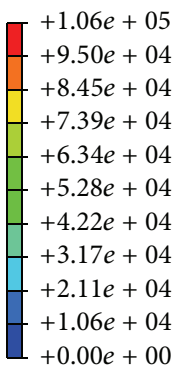

CNORMF

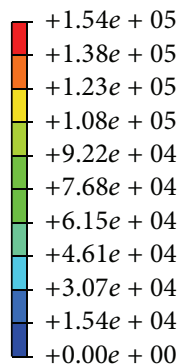

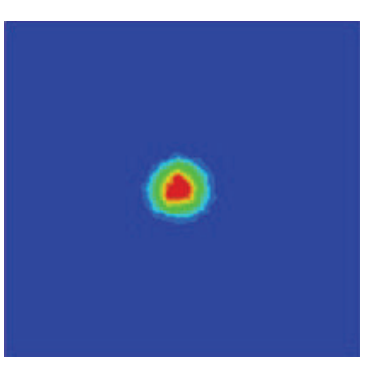

FIGURE 8: Normal contact-force nephogram when the thickness of the EPS concrete buffer layer is equal to $0.6 \mathrm{~m}$ and the impact velocity is equal to $4 \mathrm{~m} / \mathrm{s}$ (unit: $\mathrm{Pa}$ ).

layer is larger, and the protection is better compared to the rigid debris dam.

\subsection{The Relation between the Thickness of the Buffer}

Layer and $\Delta F_{i 0-k}$ and the Relation between the Thickness of the Buffer Layer and the Equivalent Plastic Strain of the Rigid Debris Dam

5.2.1. The Changes of Maximum Normal Contact Force and Stress on the Rigid Debris-Dam Node with Different Impact Velocities under Different Buffer Layer Thicknesses. The changes of the maximum normal contact force and stress on the rigid debris-dam node with different impact velocities under different thicknesses of buffer layers are shown in Figures 11 and 12.

Figures 11 and 12 show that the contact force and the contact stress to the debris-dam node have the same trend as the velocity of the massive stone at different thicknesses of buffer layers. The contact force and the contact stress to the debris-dam node increase as the velocity of the massive stone increases. When the stone directly impacts the rigid debris dam, the contact force of the debris-dam contact surface and the contact stress to the debris-dam node are far greater than when a stone with the same velocity impacts the rigid debris dam with the buffer layer. Moreover, under the same impact velocity, the contact force and the contact stress to the debris-dam node decrease as the thickness of the buffer layer increases.

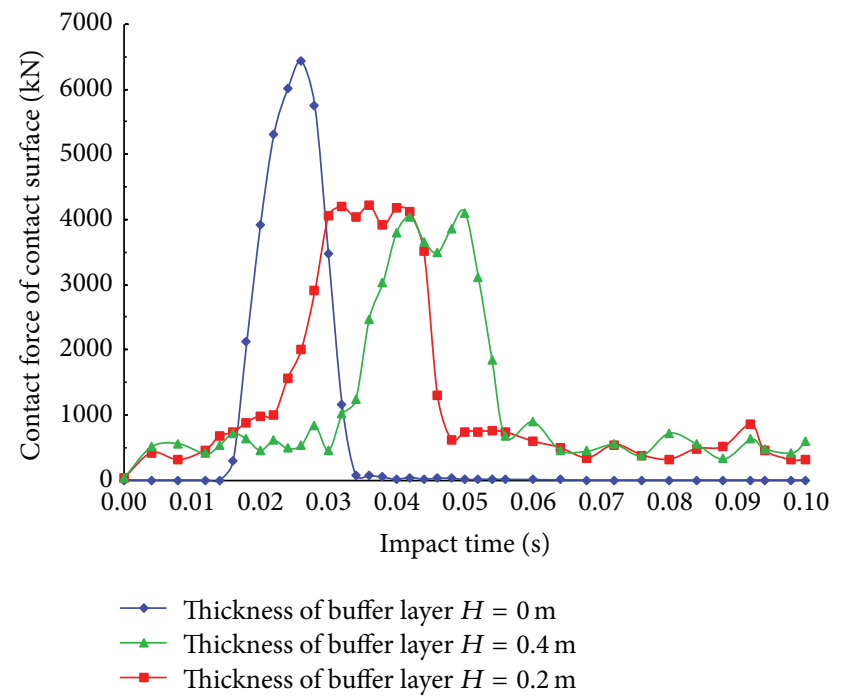

FIGURE 9: The time-history curve of the normal contact force when the impact velocity is equal to $4 \mathrm{~m} / \mathrm{s}$ and the thickness of the EPS concrete buffer layer is equal to $0 \mathrm{~m}, 0.2 \mathrm{~m}$, or $0.4 \mathrm{~m}$.

5.2.2. The Relation between the Thickness of Buffer Layer and $\Delta F_{i 0-k}$. To express the effect of the EPS concrete buffer layer thickness for the contact force to the rigid debris-dam node more clearly, the contact force for the rigid debrisdam node with no buffer layer is subtracted from the contact force for the rigid debris-dam node with different thicknesses of EPS concrete buffer layers. $\Delta F_{i j-k}$ is the reduction of 


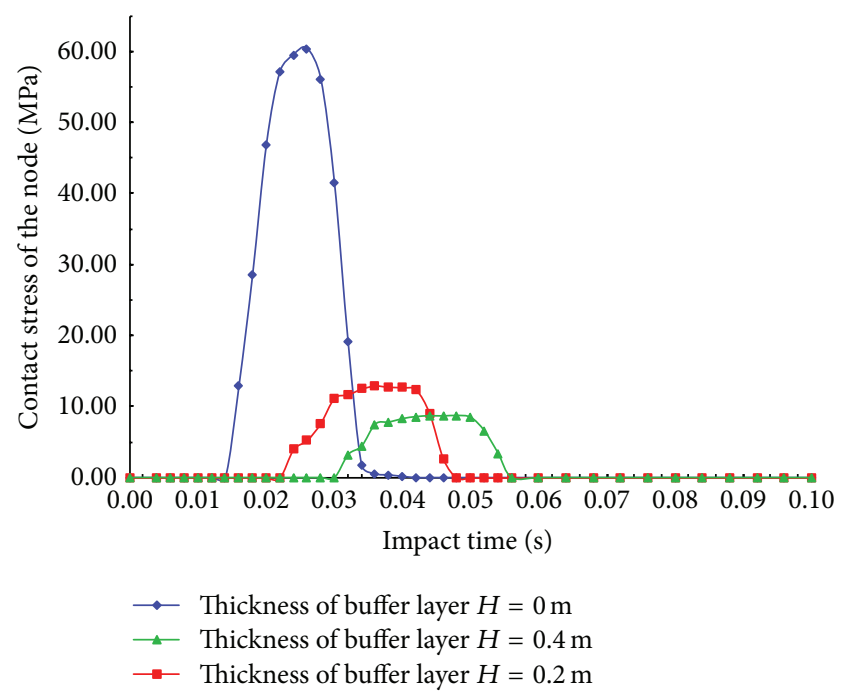

FIGURE 10: The time-history curve of the contact stress on the node with the maximum contact stress when the impact velocity is equal to $4 \mathrm{~m} / \mathrm{s}$ and the thickness of the EPS concrete buffer layer is equal to $0 \mathrm{~m}, 0.2 \mathrm{~m}$, or $0.4 \mathrm{~m}$.

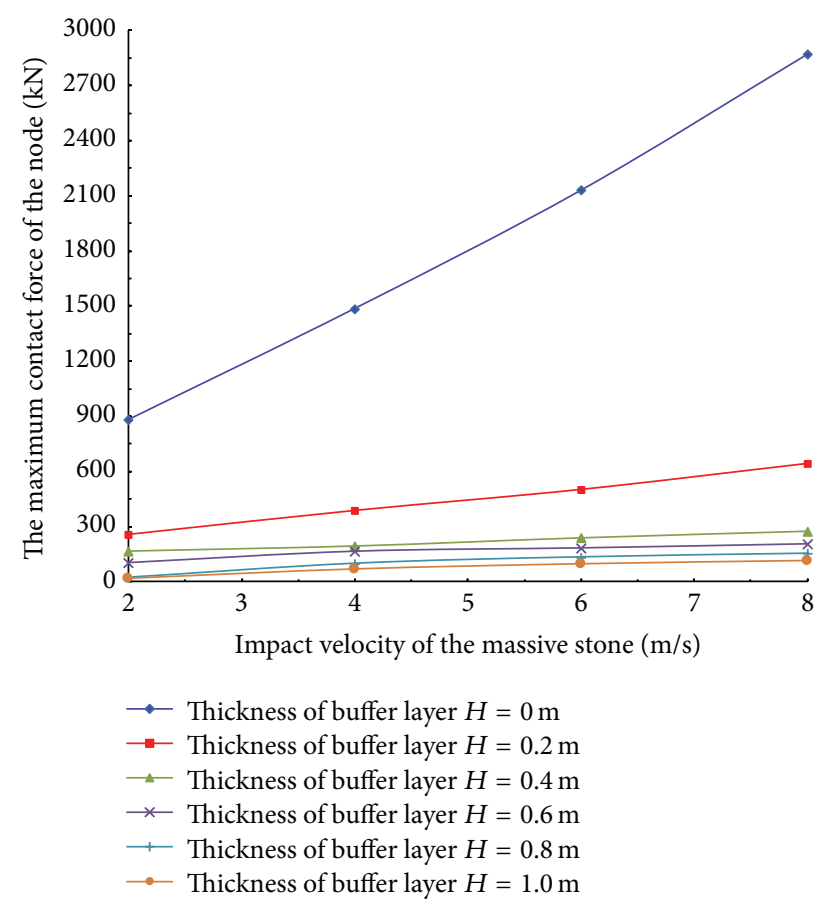

FIgURE 11: The changes of the maximum normal contact force on the rigid debris-dam node with different impact velocities under different thicknesses of buffer layers.

the maximum contact force (stress) of the debris-dam node when the massive stone impacts the rigid debris dam. When $\Delta F_{i j-k}$ is larger, the buffering effect is better. The mathematical expression of $\Delta F_{i j-k}$ is as follows:

$$
\Delta F_{i j-k}=F_{i 0-m}-F_{i j-k},
$$

where $F_{i 0-m}$ is the maximum contact force (stress) of debrisdam node $m$ when a massive stone with velocity $i$ directly

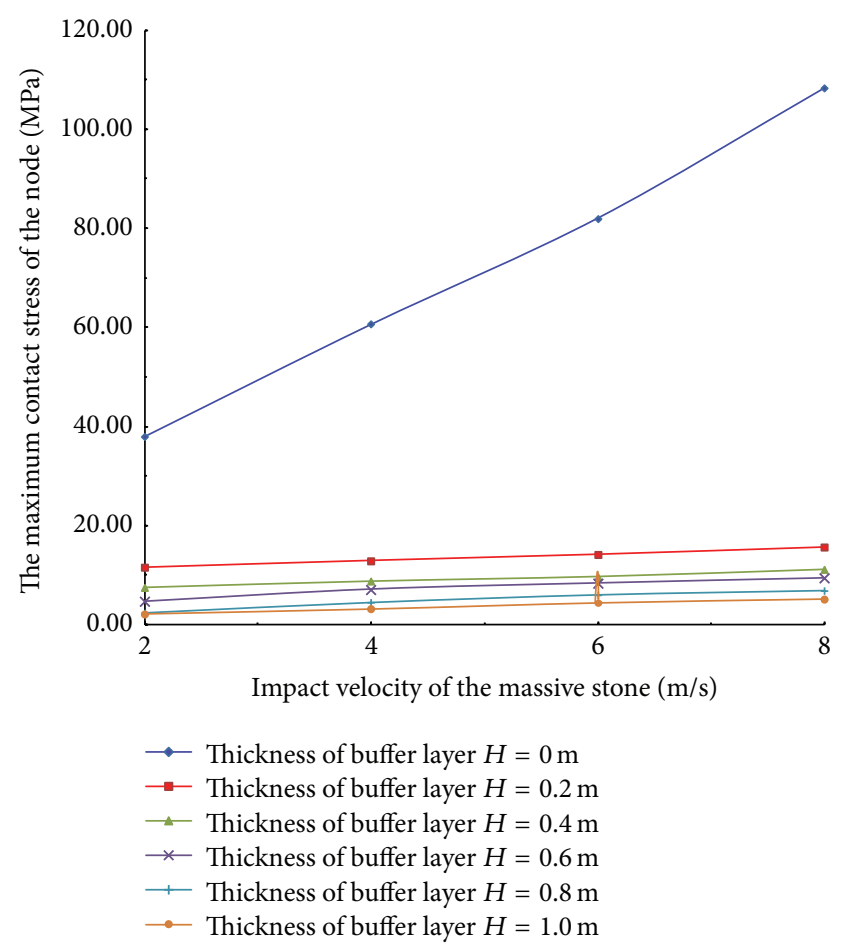

FIGURE 12: The changes of the maximum normal contact stress on the rigid debris-dam node with different impact velocities under different thicknesses of buffer layers.

impacts the rigid debris dam, $\mathrm{KN}(\mathrm{Pa}), i$ is the normal velocity $(\mathrm{m} / \mathrm{s}), m$ is the node of the rigid debris dam with the maximum contact force (stress), $F_{i j-k}$ is the maximum contact force (stress) of the debris-dam node $k$ when a massive stone with velocity $i$ impacts the rigid debris dam with a EPS concrete buffer layer of a thickness equal to $j m$, $\mathrm{KN}(\mathrm{Pa}), j$ is the thickness of the EPS concrete buffer layer, $j=0.2,0.4,0.6,0.8$, or $1 \mathrm{~m}$, and $k$ is the node of the rigid debris dam with the maximum contact force (stress) and the rigid debris dam with an EPS concrete buffer layer of $j \mathrm{~m}$.

The relation curves between $\Delta F_{i 0-k}$ and the buffer layer thickness $(H)$ are shown in Figures 13 and 14 when the impact velocity of a massive stone is $2 \mathrm{~m} / \mathrm{s}, 4 \mathrm{~m} / \mathrm{s}, 6 \mathrm{~m} / \mathrm{s}$, and $8 \mathrm{~m} / \mathrm{s}$.

Figures 13 and 14 show that the reduction of the maximum contact force and the maximum contact stress on the debrisdam node follow the same trend with the changing buffer layer thickness under different velocities of the massive stone. The reduction of the maximum contact force and the maximum contact stress increase as the thickness of the buffer layer increases. Taking the impact velocity $(V=4 \mathrm{~m} / \mathrm{s})$ of the massive stone, for example, the reduction of the maximum contact force on the debris-dam node ranges from $1,097.98 \mathrm{kN}$ to $1,415.48 \mathrm{kN}$, whereas the thickness of the buffer layer ranges from $0.2 \mathrm{~m}$ to $1 \mathrm{~m}$, and the reduction of the maximum contact stress to the debris-dam node ranges from $4.77 \mathrm{MPa}$ to $5.74 \mathrm{MPa}$. From this, we reach the conclusion that, with the other conditions remaining constant, the buffering effect of the rigid debris dam improves as the buffer layer thickness increases. 


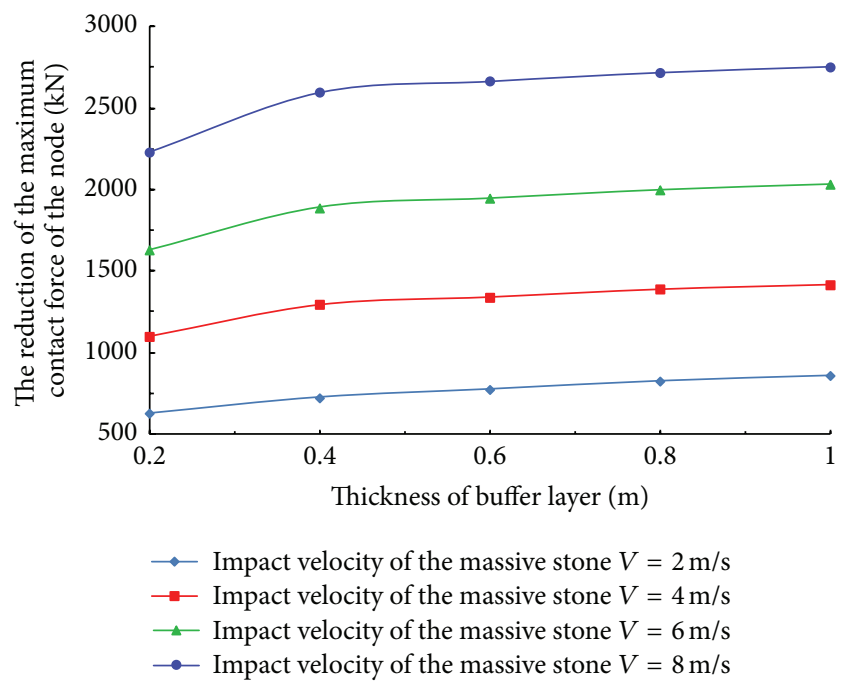

FIGURE 13: The relation curve between the reduction of the maximum contact force $\left(\Delta F_{i 0-k}\right)$ and the buffer layer thickness $(H)$ when the impact velocity of a massive stone is $2 \mathrm{~m} / \mathrm{s}, 4 \mathrm{~m} / \mathrm{s}, 6 \mathrm{~m} / \mathrm{s}$, and $8 \mathrm{~m} / \mathrm{s}$.

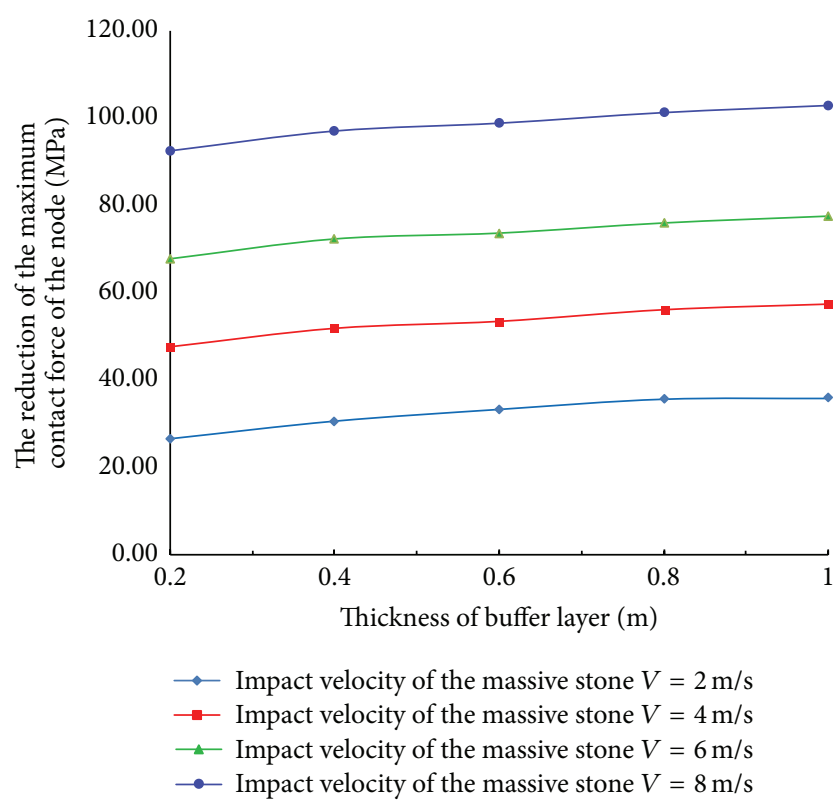

FIGURE 14: The relation curve between the reduction of the maximum contact stress $\left(\Delta F_{i 0-k}\right)$ and the buffer layer thickness $(H)$ when the impact velocity of a massive stone is $2 \mathrm{~m} / \mathrm{s}, 4 \mathrm{~m} / \mathrm{s}, 6 \mathrm{~m} / \mathrm{s}$, and $8 \mathrm{~m} / \mathrm{s}$.

5.2.3. The Relation between the Thickness of the Buffer Layer and the Equivalent Plastic Strain. To further evaluate the effect of buffer layer thickness on the cushioning properties of the rigid debris dam under different impact velocities of massive stones, the relation curve between the thickness of the EPS concrete buffer layer and the equivalent plastic deformation of the rigid debris dam is shown in Figure 15.

From Figure 15, we obtain the following conclusions. When a massive stone with a speed of $2 \mathrm{~m} / \mathrm{s} \sim 8 \mathrm{~m} / \mathrm{s}$ directly impacts a rigid debris dam, the rigid debris dam generates

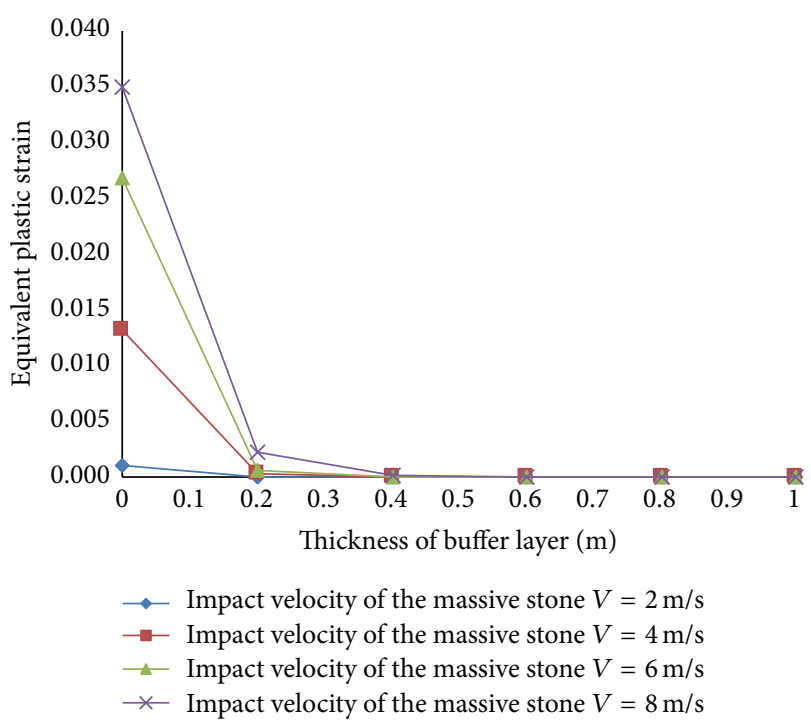

FIGURE 15: The relation curve between the thickness of the EPS concrete buffer layer and the equivalent plastic deformation of the rigid debris dam.

different degrees of equivalent plastic strain. When the thickness of the EPS concrete buffer layer is not less than $0.6 \mathrm{~m}$, there is no equivalent plastic strain for a rigid debris dam that is impacted by a massive stone with a velocity of less than $4 \mathrm{~m} / \mathrm{s}$. When the thickness of the EPS concrete buffer layer is not less than $0.8 \mathrm{~m}$, there is no equivalent plastic strain for a rigid debris dam that is impacted by a massive stone with a velocity of less than $6 \mathrm{~m} / \mathrm{s}$. Finally, when the thickness of the EPS concrete buffer layer is not less than $1.0 \mathrm{~m}$, there is no equivalent plastic strain for a rigid debris dam that is impacted by a massive stone with a velocity of less than $8 \mathrm{~m} / \mathrm{s}$. The EPS concrete buffer layer, with its large plastic deformation, can protect the rigid debris dam to avoid the destruction caused by a massive stone.

5.3. The Recommended Formula for the Optimum Thickness of the Buffer Layer and the Impact Velocity of a Massive Stone. In the EPS concrete buffer layer's allowable working range, the thickness of the buffer layer has little influence on the cushioning performance; however, beyond the allowable range, the buffer performance increases as the thickness of the buffer layer increases. In the debris-dam protection project, the thickness of the EPS concrete cannot be too great. To make the EPS concrete buffer layer act as a better cushion and to maximize its performance to meet the needs of the project and to maintain rigid debris dams with no equivalent plastic deformation, the recommended formula between the optimum thickness of the buffer layer and the impact velocity of a massive stone is given as follows:

$$
\begin{aligned}
\text { When } 0 \leq V \leq 4 \mathrm{~m} / \mathrm{s}, & H=0.6 \mathrm{~m} \\
\text { When } 4 \mathrm{~m} / \mathrm{s} \leq V \leq 6 \mathrm{~m} / \mathrm{s}, & H=0.8 \mathrm{~m} \\
\text { When } 6 \mathrm{~m} / \mathrm{s} \leq V \leq 8 \mathrm{~m} / \mathrm{s}, & H=1 \mathrm{~m} .
\end{aligned}
$$


The relation between the impact energy and impact velocity of the massive stone is given in formula (1) and thus, recommended formula (16) can also be expressed in the following formula:

$$
\begin{array}{rr}
\text { When } 0 \leq Q \leq 89.042 \mathrm{KJ}, & H=0.6 \mathrm{~m} \\
\text { When } 89.042 \mathrm{KJ} \leq Q \leq 200.010 \mathrm{KJ}, & H=0.8 \mathrm{~m} \\
\text { When } 200.010 \mathrm{KJ} \leq Q \leq 355.097 \mathrm{KJ}, & H=1 \mathrm{~m} .
\end{array}
$$

\section{Conclusion}

Based on the cushioning properties of EPS concrete, EPS concrete as a buffer layer poured on the surface of a rigid debris dam is proposed. A three-dimensional numerical calculation model of an EPS concrete buffer layer/rigid debris dam is established. According to the theory of a single factor, numerical simulation reveals that, with respect to the maximum impact force of the surface of a rigid debris dam, the rules change with the thickness of the buffer layer. The simulation results show the following:

(1) The EPS concrete buffer layer can effectively extend the impact time of a massive stone and reduce the impact force of the debris flow on the rigid debris dam due to the stone.

(2) In the EPS concrete buffer layer allowable working range, the thickness of the buffer layer has little influence on the cushioning performance; however, beyond the allowable range, the buffer performance increases as the thickness of the buffer layer increases.

(3) According to the results of the numerical simulation, the recommended formula for the optimum thickness of the buffer layer is obtained.

\section{Conflict of Interests}

The authors declare that there is no conflict of interests regarding the publication of this paper.

\section{Acknowledgments}

This paper is financially supported by Focus Deploying Projects of Chinese Academy of Sciences (Grant no. KZZDEW-05-01-04) and National Key Technology R\&D Program of the Ministry of Science and Technology (2014BAL05B01).

\section{References}

[1] Y. You, X. C. Chen, and J. F. Liu, “'8.13' extra large debris flow disaster in Wenjia Gully of Qingping Township, Mianzhu, Sichuan Province," Journal of Catastrophology, vol. 26, no. 4, pp. 68-72, 2011.

[2] G. S. Hu, N. S. Chen, M. F. Deng et al., "Analysis of the characteristics of impact force of massive stones of the Sanyanyu debris flow gully in Zhouqu, Gansu Province," Earth and Environment, vol. 39, no. 4, pp. 478-484, 2011.

[3] X. Q. Chen, Y. You, P. Cui et al., "New control methods for large debris flows in Wenchuan earthquake area," Journal of Sichuan
University (Engineering Science Edition), vol. 45, no. 1, pp. 14-22, 2013.

[4] X. L. Wang and G. Z. Zheng, "Study on impact resistance of new support with spring and its application in Debris Flow Dam," China Safety Science Journal, vol. 23, no. 2, pp. 3-9, 2013.

[5] Z. S. Lan, G. Y. Cao, and D. J. Yao, "Foreign debris flow dam engineering," Debris Flow (Chengdu), no. 2, pp. 76-84, 1983.

[6] J. Su, C. Zhou, S. S. Chen et al., "Numerical simulation of flexible gabion arch dam to prevent and control debris flow blocks," Chinese Journal of Geotechnical Engineering, vol. 37, no. 2, pp. 269-275, 2015.

[7] X. Luo, S. Q. Shi, Q. P. Yan et al., "Numerical analysis of rock fall prevention using discarded tires," The Chinese Journal of Geological Hazard and Control, vol. 22, no. 4, pp. 36-40, 2011.

[8] Z.-L. Wang, Y.-C. Li, and J. G. Wang, "Numerical analysis of attenuation effect of EPS geofoam on stress-waves in civil defense engineering," Geotextiles and Geomembranes, vol. 24, no. 5, pp. 265-273, 2006.

[9] J. G. Wang, W. Sun, and S. Anand, "Numerical investigation on active isolation of ground shock by soft porous layers," Journal of Sound and Vibration, vol. 321, no. 3-5, pp. 492-509, 2009.

[10] D. P. Wang, The study on the dynamic response of rockfall impact rock-shed and the mechanism of energy dissipation [Ph.D. thesis], University of Chinese Academy of Sciences, Beijing, China, 2013.

[11] J. C. Serrano-Perez, U. K. Vaidya, and N. Uddin, "Low velocity impact response of autoclaved aerated concrete/CFRP sandwich plates," Composite Structures, vol. 80, no. 4, pp. 621-630, 2007.

[12] J. Hu, Research on mechanica properties and anti-explosion, seismic performance of EPS concrete [Ph.D. dissertation], University of Science and Technology of China, 2011.

[13] P. H. Bischoff, K. Yamura, and S. H. Perry, "Polystyrene aggregate concrete subjected to hard impact," ICE Proceedings, vol. 89, no. 2, pp. 225-239, 1990.

[14] K. G. Babu and D. S. Babu, "Behaviour of lightweight expanded polystyrene concrete containing silica fume," Cement \& Concrete Research, vol. 33, no. 5, pp. 755-762, 2003.

[15] B. Chen and L. Z. Chen, "Study on the mechanical properties of light weight expanded polystyrene concrete," China Concerete and Cement Products, vol. 3, no. 4, pp. 50-55, 2004.

[16] B. Chen, S.-Y. Tu, and Y.-F. Weng, "Study on the properties of lightweight expanded polystyrene concrete," Journal of Building Materials, vol. 10, no. 1, pp. 26-31, 2007.

[17] X.-B. Yu, X.-Q. Chen, and J.-G. Chen, "Finite element analysis of the concrete gravity debris dam by impact effect of the massive stone in the debris flow," Electronic Journal of Geotechnical Engineering, vol. 19, pp. 2779-2790, 2014.

[18] S. He, X. Li, and Y. Wu, "Calculation of impact force of outrunner blocks in debris flow considering elastoplastic deformation," Chinese Journal of Rock Mechanics and Engineering, vol. 26, no. 8, pp. 1664-1669, 2007.

[19] S.-M. He, Y. Wu, and J. Shen, "Simplified calculation of impact force of massive stone in debris flow," Journal of Natural Disasters, vol. 18, no. 5, pp. 51-55, 2009.

[20] X. J. Peng, A. L. Yu, and F. Youzhen, "An analysis on parameters for concrete damage plasticity model," Journal of Suzhou University of Science and Technology (Engineering and Technology), vol. 23, no. 3, pp. 40-43, 2010.

[21] W. Y. Zhou, Advanced Rock Mechanics, China Water \& Power Press, Beijing, China, 1986. 
[22] B. F. Zhu, Principle and Application of Finite Element Method, China Water \& Power Press, Beijing, China, 2009.

[23] J. Liu, L. F. Zeng, Y. J. Ji et al., Mechanical Mechanism and Numerical Simulation of Casing Damage in Thermal Production Oilfield, Science Press, Beijing, China, 2013.

[24] J. N. Yue and J. J. Liu, "Numerical simulation of drainage process or sand cushion in saturated asphalt pavement," Electronic Journal of Geotechnical Engineering, vol. 17, pp. 3905-3914, 2012.

[25] J. Liu, R. Song, and J. Zhao, "Numerical simulation research on seepage mechanism in pore-scale deformable porous media," Disaster Advances, vol. 6, supplement 1, pp. 49-58, 2013.

[26] S.-M. He, J. Shen, and Y. Wu, "Rock shed dynamic response to impact of rock-fall," Rock and Soil Mechanics, vol. 32, no. 3, pp. 781-788, 2011.

[27] D. S. Simulia, Abaqus6.12 Help Documentation, Dassault Systems Simulia, Providence, RI, USA, 2012.

[28] X. F. Liao, Z. Xu, and J. Wang, "A strengthening method of double-curved arch bridge based on EPS concrete," Journal of University of Jinan (Science \& Technology), vol. 28, no. 5, pp. 391394, 2014.

[29] D.-P. Wang, S.-M. He, C.-J. Ouyang, X.-X. Zhang, B. Xiang, and X.-F. Wang, "Study of dynamic response of shed reinforced concrete slab to impact load of rock-fall," Rock and Soil Mechanics, vol. 34, no. 3, pp. 881-886, 2013.

[30] T. Lei, J. Qian, and C. Q. Liu, "Application of damaged plasticity model for concrete," Structural Engineers, vol. 24, no. 2, pp. 2227, 2008. 

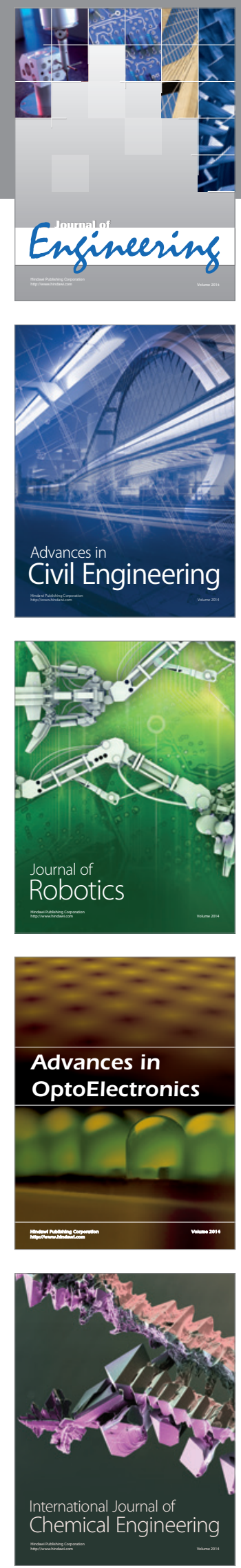

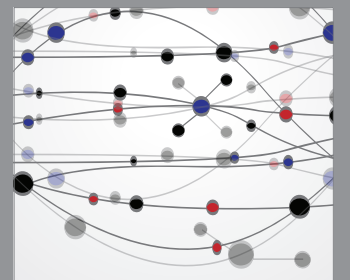

The Scientific World Journal
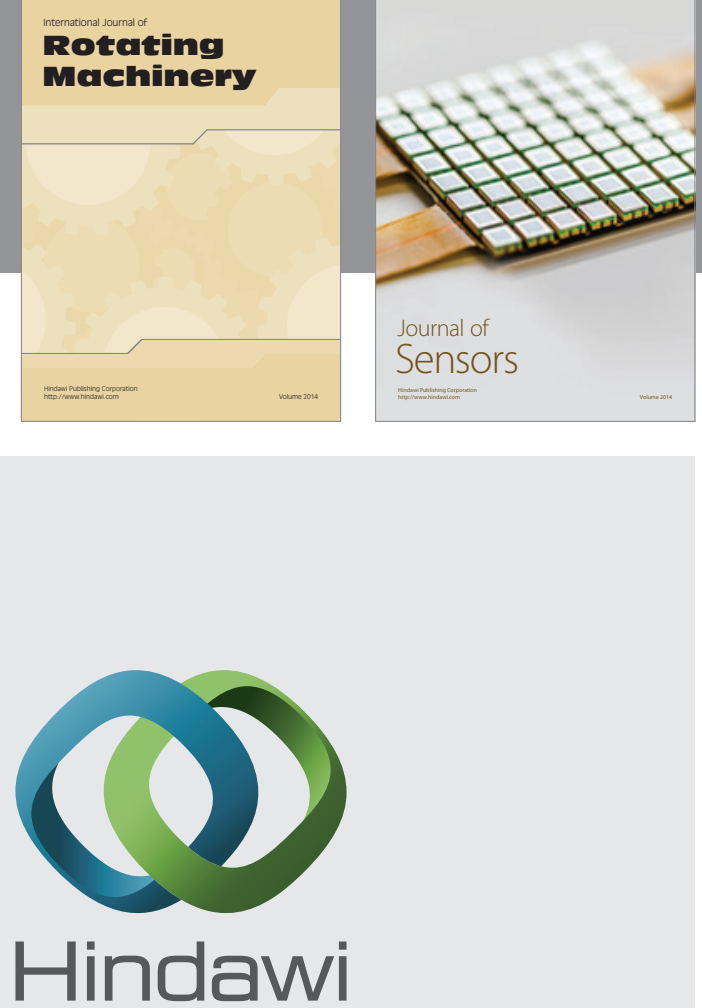

Submit your manuscripts at http://www.hindawi.com
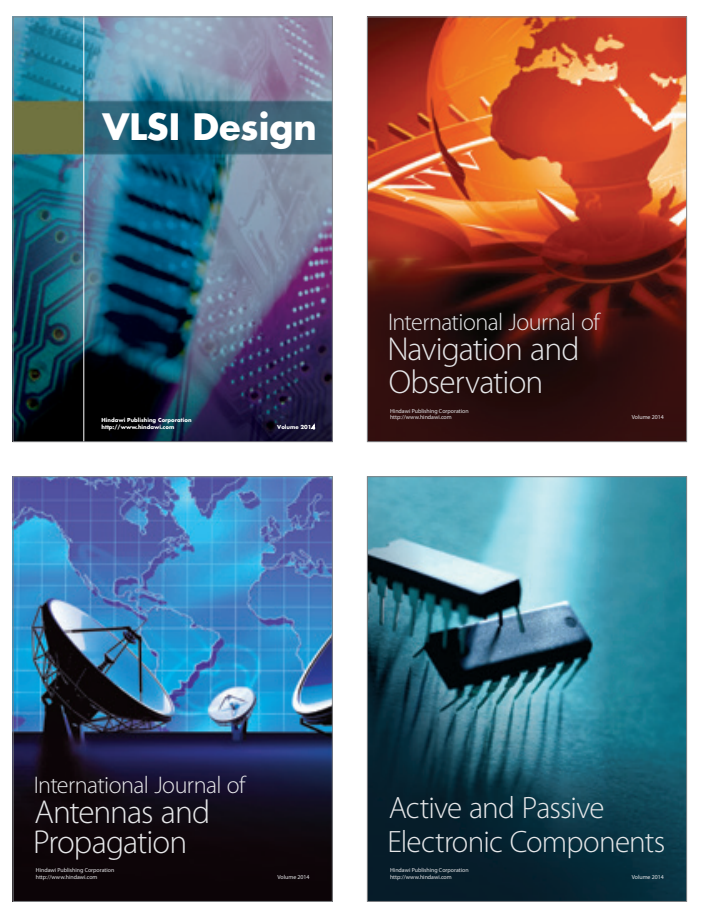
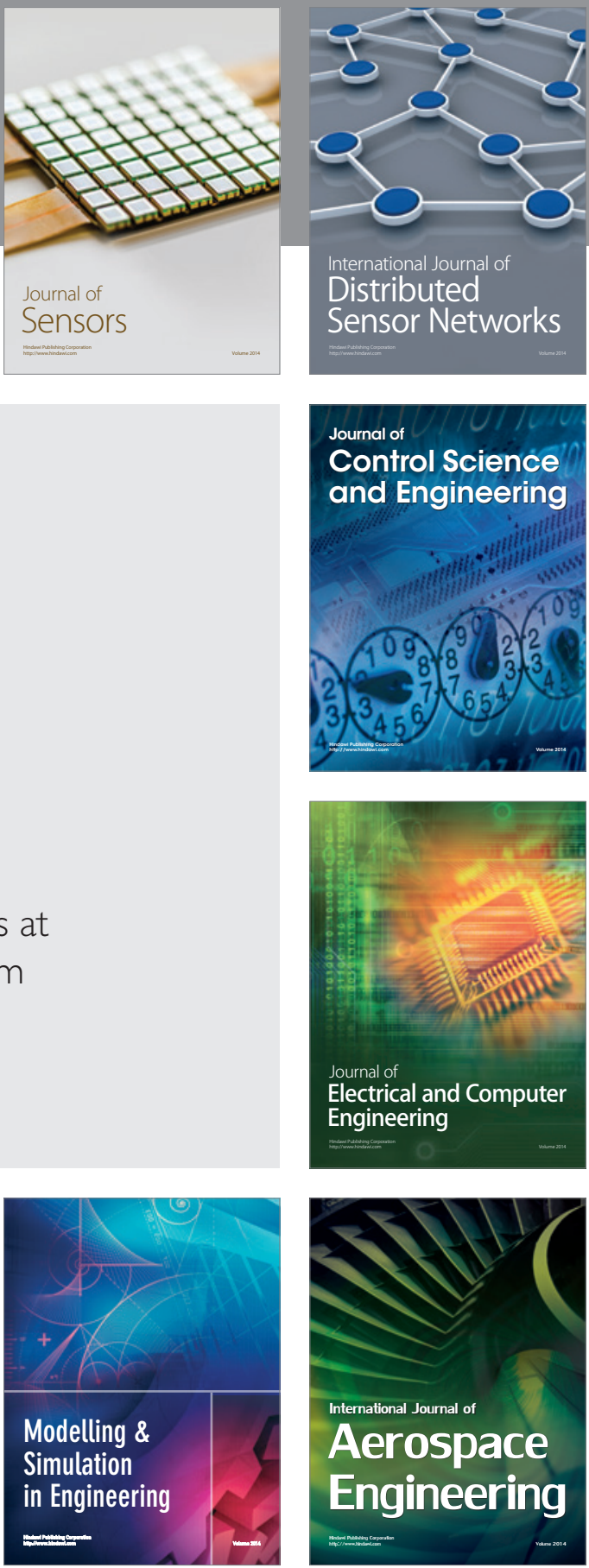

Journal of

Control Science

and Engineering
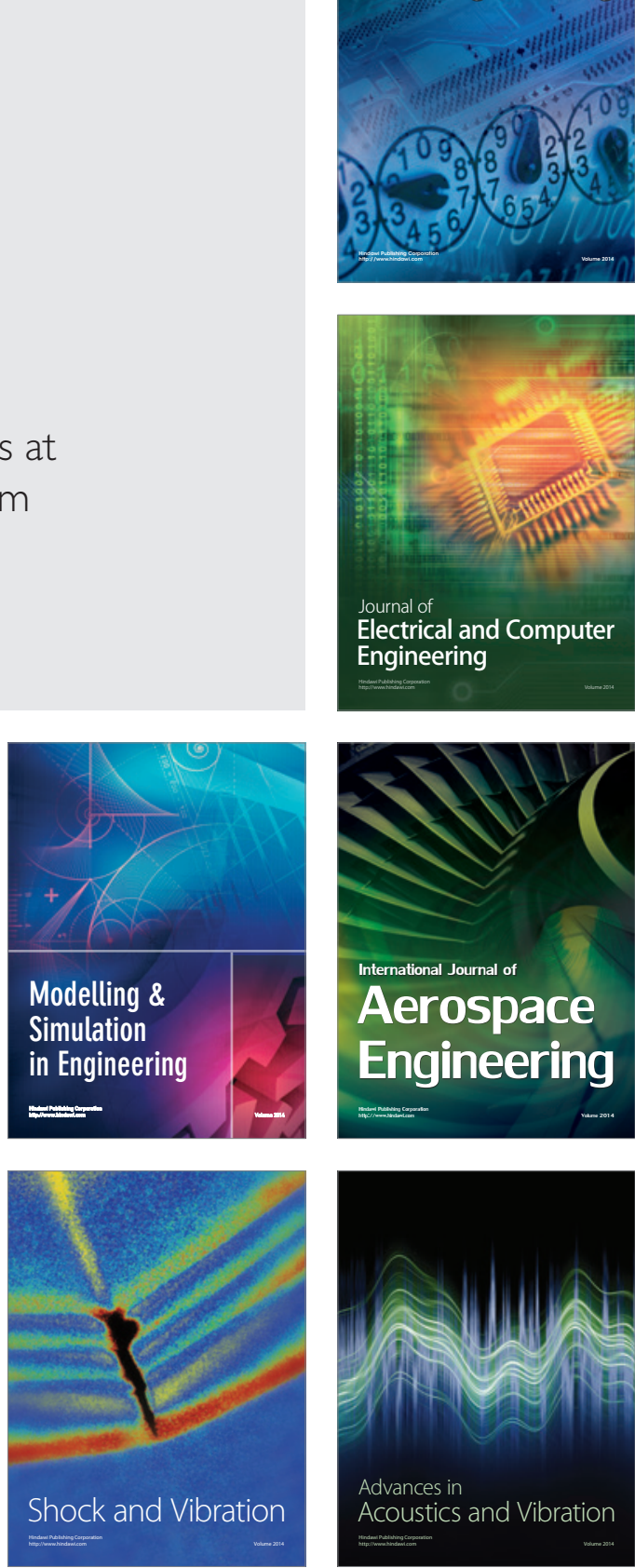